\title{
Transkranial likestrømsstimulering ved kroniske smerter
}

\begin{abstract}
BAKGRUNN Transkranial likestrømsstimulering (Transcranial Direct Current Stimulation, tDCS) er en ikke-invasiv nevromodulerende metode. Gjennom å endre hvilemembranpotensialet i nevroner kan man ved hjelp av denne metoden endre aktiviteten i områder av hjernen. Vi ønsket derfor å gjennomgå randomiserte, kontrollerte studier der man har undersøkt behandlingseffekten av transkranial likestrømsstimulering på kroniske smerter.
\end{abstract}

KUNNSKAPSGRUNNLAG Vi gjorde et søk i PubMed med søkeordene «transcranial direct current stimulation» og «pain», med filteret «randomized controlled trial».

RESULTATER Fem randomiserte kliniske studier der kvantitative utfallsmål for smerte var benyttet ble identifisert. Studiene representerte svært ulike grupper av smertepasienter. Noen av studiene viste at stimulering med transkranial likestrømsstimulering førte til betydelig lavere smertenivå, men samlet var ikke resultatene entydige.

FORTOLKNING Metoden bør unders $\emptyset$ kes ytterligere i studier med klart definerte grupper av smertepasienter og flere deltakere, før man vurderer implementering av den som behandlingsalternativ ved kroniske smerter.

Kronisk smerte defineres ofte som en vedvarende smertetilstand med varighet $\mathrm{i}$ over 12 uker (1) og har i Europa en prevalens på om lag $20 \%(2,3)$. Det mangler effektiv behandling for mange av de kroniske smertetilstandene (4). Høy forekomst og mangel på virksom behandling av kroniske smerter har samfunnsmessige konsekvenser, gjennom stort trykk på velferdssystemene $(5,6)$, og personlige konsekvenser, i form av depresjon og redusert livskvalitet (7).

Eksempelvis er fibromyalgi et kronisk smertesyndrom med prevalens på 3-5\% (8), med høyere forekomst hos kvinner enn hos menn. Patofysiologien til denne tilstanden er ikke fullstendig kartlagt, men det antas at sentralnervøs sensitivering kan spille en rolle (9). Resultater fra undersøkelser med stadig mer avanserte hjerneavbildningsteknikker og teoretisk forståelse av en mulig sentralnervøs felleskomponent i kronisk smerte (10) har sannsynliggjort at modulering av sentralnervesystemets funksjon kan påvirke smertepersepsjonen.

Transkranial likestrømsstimulering (Transcranial Direct Current Stimulation, tDCS) er en ikke-invasiv hjernestimuleringsmetode som endrer nevronets eksitabilitet, altså gir en endring i mengden aksjonspotensialer som må nå nevronet før det når terskelen for utløsning av eget aksjonspotensial $(11,12)$. Metoden har det siste tiåret vakt økende interesse hos forskere og klinikere. Den eksakte distribusjonen av elektriske felter $\mathrm{i}$ hjernen under stimulering er ikke kartlagt, men datasimulering $(13,14)$ indikerer at elektrodeplasseringen påvirker de områdene av hjernen stimuleringen er tiltenkt å endre. Den nevromodulerende effekten av stimuleringen på fysiologiske responser er demonstrert eksperimentelt (15).

Tilgjengelige data tyder på at metoden trygt kan brukes på mennesker (16) og at den har begrensede bivirkninger (17). På dette grunnlaget kan man konkludere med at det teoretiske grunnlaget for klinisk utprøvning er etablert. Metodologisk er transkranial likestrømsstimulering velegnet for forskning, og ettersom metoden er lite fysisk merkbar, kan den enkelt placebokontrolleres $i$ en dobbeltblind design (18).

Tidlige faser av kliniske studier har vist at behandlingen potensielt kan brukes ved epilepsi $(19,20)$, alvorlig depresjon $(21,22)$ og rusavhengighet (23-25). I tillegg kan stimuleringen fasilitere motorisk funksjon etter hjerneslag $(26,27)$ og hukommelsesfunksjon ved Alzheimers sykdom (28).

I denne oversiktsartikkelen presenteres transkranial likestrømsstimulering som behandlingsmetode, og vi oppsummerer resultater fra forskning på bruk av metoden ved kroniske smertetilstander.

\section{Kunnskapsgrunnlag}

Bakgrunnsinformasjonen om transkranial likestrømsstimulering bygger på et skjønnsmessig utvalg av artikler, valgt ut fra forfatternes forskning og erfaring innen feltet. For å vurdere effekt av behandlingsmetoden på kronisk smerte i kliniske studier ble det gjennomført et søk i PubMed med søkeordene «transcranial direct current stimulation» og «pain», med filteret «randomized controlled trial». Søket ble gjennomført 19.11. 2012 og ga 19 treff.

Teoretiske artikler som ikke inneholdt resultater $(n=3)$, studier på friske frivillige

\author{
Asbjørn J. Fagerlund \\ a.j.fagerlund@unn.no \\ Smerteavdelingen \\ OPIN-klinikken \\ Universitetssykehuset Nord-Norge \\ og \\ Institutt for psykologi \\ Universitetet i Troms $\varnothing$

\section{Martin K. Bystad} \\ Alderspsykiatrisk avdeling \\ Universitetssykehuset Nord-Norge \\ og \\ Institutt for psykologi \\ Universitetet i Tromsø \\ Per M. Aslaksen \\ Institutt for psykologi \\ Universitetet i Troms $\varnothing$
}

Se også kunnskapsprøve

på www.tidsskriftet.no

Podkast på www.tidsskriftet.no

> Se også side 2225

\section{HOVEDBUDSKAP}

Kroniske smerter er vanlig, og behandlingen kan være krevende

Transkranial likestrømsstimulering er en ikke-invasiv behandlingsmetode som endrer hvilemembranpotensialer i områder av hjernen

Resultatene fra tidlige kliniske studier viser mulig effekt på kroniske smerter. Dette bør føre til videre klinisk utprøvning 
( $\mathrm{n}=5$ ) og studier der man målte behandlingseffekt på andre tilstander enn kronisk smerte $(n=4)$ ble ekskludert. Etter dette gjensto det sju artikler. I en av disse studiene ble transkranial likestrømsstimulering kombinert med en annen behandlingsmetode, men det var ingen gruppe som kun fikk stimuleringen, og artikkelen ble ekskludert. Ytterligere en studie ble ekskludert fordi den brukte samme datagrunnlag (29) som en annen (30). Fem artikler ble til slutt inkludert.

\section{Administrering og virkemåte}

Transkranial likestrømsstimulering gjøres ved at man fester to eller flere elektroder til hodebunnen. Plasseringen bestemmes av hvilke deler av hjernen man ønsker å stimulere. Strømstyrken er under terskelen for utløsning av aksjonspotensialer, men påvirker nevronene ved å endre hvilemembranpotensialet (31). Normalt bestemmer summen av inhibitoriske og eksitatoriske signaler om membranpotensialet $\mathrm{i}$ nevronet når terskelen for at aksjonspotensialet utløses. En depolarisering av hvilemembranpotensialet fører til at forskjellen i spenning mellom hvilemembranpotensial og terskel for utløsing av aksjonspotensial blir mindre. Dette betyr at det skal et svakere samlet signal til for å depolarisere nevronet til terskelen for utløsning av aksjonspotensial. Dette fører til økt nevral aktivitet.

Stimuleringen kan være katodal eller anodal. Den funksjonelle forskjellen er at anodal stimulering reduserer avstanden mellom hvilemembranpotensial og terskel i et område av cortex, mens katodal stimulering øker den (15). Resultatet er at den nevrale aktiviteten $\mathrm{i}$ stimulerte områder blir hevet eller senket. Dersom stimuleringen gjentas over flere dager, vil endringer i eksitabilitet akkumuleres (32). Langtidseffekten av den transkraniale likestrømsstimuleringen er sannsynligvis et resultat av plastiske endringer (11) i form av langtidspotensiering, altså forsterking av signaloverføringen mellom nevroner.

Den kliniske stimuleringen skjer vanligvis ved $1-2 \mathrm{~mA} \mathrm{i} 10-30$ minutter. Til sammenlikning leverer moderne ECT-konvulsatorer (til elektrokonvulsiv behandling) inntil $900 \mathrm{~mA}$ i 8 sekunder (33). Peroralt inntak av $100 \mathrm{mg}$ D-cyklocerin, en partiell N-metyl-D-aspartat-agonist (NMDA-agonist), to timer før stimulering fører til større varighet $i$ eksitabilitetsendringer i det stimulerte området (34). Dette støtter antakelsen at langtidseffekten av likestrømsstimuleringen skjer gjennom nevroplastiske mekanismer, ettersom NMDA-reseptorer er sentrale i langtidspotensiering.

Placebostimulering utføres vanligvis ved at man fester elektroder på samme måte som ved aktiv stimulering. Deretter stimulerer man i 30 sekunder før gradvis avbrudd. Dette er en stimuleringslengde som ikke gir målbare effekter (35). Ved aktiv stimulering vil den som blir behandlet venne seg til fornemmelsen av strømstimulering etter omtrent like lang tid. På denne måten vil pasientens opplevelse av aktiv behandling og placebobehandling være lik. Forsøksdeltakere uten erfaring med behandlingsmetoden klarer vanligvis ikke å skille mellom betingelsene (18).

En gjennomgang av 567 behandlingssesjoner i et ledende forskningsmiljø innen ikke-invasiv hjernestimulering (36) viste at ingen pasienter eller friske frivillige ønsket stimuleringen avbrutt på grunn av ubehag. De vanligste rapporterte bivirkningene er søvnighet, kløe under elektrodene og forbigående rød hud på stimuleringsstedet. Stimulering etter dagens etablerte protokoller anses som trygge, men grundig kartlegging av eventuelle skadevirkninger bør vektlegges i fremtidig forskning (37).

De basalfysiologiske endringene etter transkranial likestrømsstimulering er demonstrert eksperimentelt. Metoden er enkel å administrere og synes å være trygg. Det er derfor ikke overraskende at man i flere og flere studier undersøker behandlingseffekten på tilstander der man tror avvikende aktivering $i$ hjernen kan være en del av de underliggende patofysiologiske mekanismene (fig 1) (37).

\section{Transkranial likestrømsstimulering som behandling ved kroniske smerter}

I studiene som ble gjennomgått $(30,38-41)$ varierer behandlingseffekten målt ved siste stimuleringsdag fra halvering av smerten til ingen smertereduksjon (tab 1). De inkluderte studiene er alle dobbeltblindet, placebokontrollerte og randomiserte. Smerte er målt med visuell analog skala (VAS-skala) eller numerisk skala.

Plasseringen av elektrodene, varigheten av stimuleringen og antallet behandlinger er relativt likt i studiene, noe som gjør resultatene sammenliknbare. Variasjonen i behandlingsutfall kan derfor ikke forklares av metodologiske svakheter eller forskjeller i hvordan stimuleringen ble gjennomført. I alle studiene ble det brukt anodal stimulering av primærmotorisk cortex (M1). I tillegg prøvde man i en av studiene (30) montering $\mathrm{i}$ dorsolateral prefrontal cortex (DLPFC), uten å finne signifikante effekter av dette. Det kan forklares ved at en M1montasje fører til en distribusjon av elektrisk felter som i større grad påvirker områder i hjernen som er relevante for smerteprosesseringen (14).

Forskjellene i behandlingsutfall kan heller forklares ved at det i studiene ble inkludert svært forskjellige pasientgrupper. I en

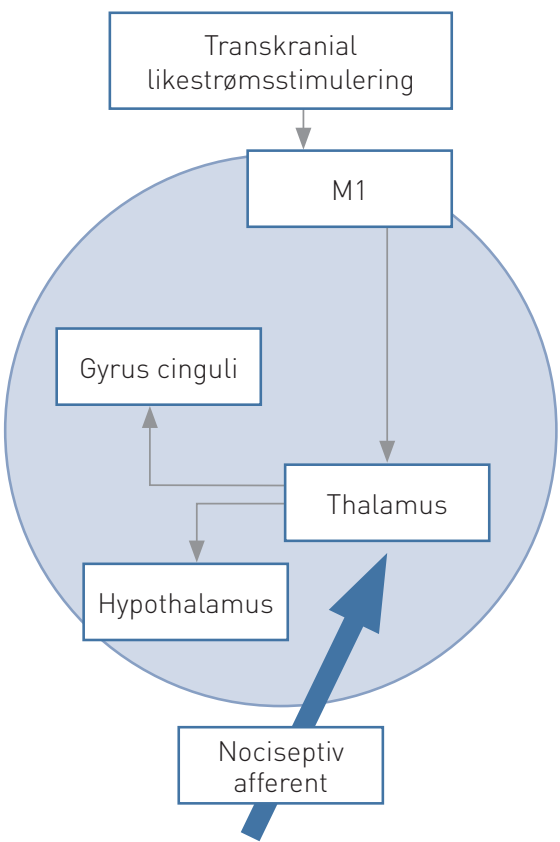

Figur 1 Hypotetiske mekanismer bak den smertehemmende effekten av transkranial likestrømsstimu lering (tDCS). Stimulering over motorisk cortex (M1) endrer hvilemebranpotensialet i nevroner i områder av hjernen, noe som kan føre til endret nevral aktivitet. Endringer i nevral aktivitet kan føre til indirekte endringer idypere strukturer slik som thalamus, som kan påvirke afferent nociseptiv signaltransmisjon. Endringer i thalamus kan også påvirke endogen smertehemming gjennom sine forbindelser til hypothalamus og områder som er sentrale i smertepersepsjonen, slik som gyrus cinguli (37)

av studiene (38) ble det brukt en overkrysningsdesign for å sammenlikne den kombinerte effekten av transkranial likestrømsstimulering og transkutan elektrisk nervestimulering (TENS). Resultatet fra betingelsen der deltakerne fikk transkranial likestrømsstimulering og placebo-TENS er gjengitt $i$ tabell 1. Det ga mindre smertereduksjon enn dersom metodene ble kombinert. I to av studiene $(30,39)$ fulgte man pasientene $i$ tre uker etter avsluttet behandling og fant at gruppen som fikk aktiv behandling også da hadde mindre smerte enn dem som hadde fått placebo. Dette er av særlig interesse, siden mulig langtidseffekt kombinert med få bivirkninger ofte trekkes frem som hovedstyrke ved behandlingsmetoden.

Eventuelle bivirkninger er rapportert i alle studiene, og det kan se ut som om stimuleringen tolereres bra av deltakerne. I en av studiene (39) ble det benyttet strukturert registrering av bivirkningenes forekomst og styrke, i de andre benyttet man åpen utspørring. Bivirkningene som hyppigst blir rapportert, er forbigående lett hodepine, tretthet og en stikkende fornemmelse under elektroden.

Selv om behandlingsmetoden ikke ser ut 
Tabell 1 Oversikt over randomiserte, kontrollerte studier der man har undersøkt behandlingseffekten av transkranial likestrømsstimulering (tDCS) og placebo sammenliknet med utgangsnivå på kroniske smerter. Samtlige studier er med anodal stimulering, ved motorisk cortex (M1) eller dorsolateral prefrontal cortex (DLPFC)

\begin{tabular}{|c|c|c|c|c|c|c|c|c|c|}
\hline \multirow{2}{*}{$\begin{array}{l}\text { Førsteforfatter, } \\
\text { publiseringsår } \\
\text { (referanse) } \\
\text { Antal, } \\
2010 \text { (39) }\end{array}$} & \multirow{2}{*}{$\begin{array}{l}\text { Diagnosegruppe } \\
\text { Ulike smertetilstander, som } \\
\text { trigeminusnevralgi, smerte } \\
\text { etter hjerneslag, artrose, } \\
\text { kroniske ryggsmerter, fibro- } \\
\text { myalgi }\end{array}$} & \multicolumn{2}{|c|}{$\begin{array}{c}\text { Antall } \\
\text { deltakere } \\
\text { (antall menn) }\end{array}$} & \multirow{2}{*}{$\begin{array}{c}\text { Strøm- } \\
\text { styrke } \\
(\mathrm{mA}) \\
1\end{array}$} & \multirow{2}{*}{$\begin{array}{l}\text { Anodens } \\
\text { plasse- } \\
\text { ring } \\
\text { M1 }\end{array}$} & \multirow{2}{*}{$\begin{array}{c}\text { Varighet } \\
\text { per } \\
\text { behandling } \\
20 \text { min }\end{array}$} & \multicolumn{2}{|c|}{$\begin{array}{c}\text { Antall } \\
\text { sesjoner } \\
\text { (antall dager) }\end{array}$} & \multirow{2}{*}{$\begin{array}{l}\text { Resultat } \\
\text { i behandlingsgruppen } \\
30 \text { \% smertereduksjon } \\
\text { fra utgangsnivå, målt } \\
\text { med visuell analog skala }\end{array}$} \\
\hline & & 23 & (6) & & & & 5 & (5) & \\
\hline $\begin{array}{l}\text { Boggio, } \\
2009(38)^{2}\end{array}$ & $\begin{array}{l}\text { Kronisk nevropatisk smerte } \\
\text { i armer }\end{array}$ & 8 & (2) & 2 & M1 & $30 \mathrm{~min}$ & 1 & (1) & $\begin{array}{l}15,5 \% \text { smertereduksjon } \\
\text { fra utgangsnivå, målt } \\
\text { med visuell analog skala }\end{array}$ \\
\hline $\begin{array}{l}\text { Fregni, } \\
2006 \text { (40) }\end{array}$ & $\begin{array}{l}\text { Kronisk smerte etter rygg- } \\
\text { margsskade }\end{array}$ & 17 & (14) & 2 & M1 & $20 \mathrm{~min}$ & 5 & (5) & $\begin{array}{l}58 \text { \% smertereduksjon } \\
\text { fra utgangsnivå, målt } \\
\text { med visuell analog skala }\end{array}$ \\
\hline \multirow[t]{2}{*}{$\begin{array}{l}\text { Fregni, } \\
2006 \text { (30) }\end{array}$} & Fibromyalgi & 32 & (0) & 2 & M1 & $20 \mathrm{~min}$ & 5 & (5) & $\begin{array}{l}59,14 \% \text { smertereduksjon } \\
\text { fra utgangsnivå, målt } \\
\text { med visuell analog skala }{ }^{1}\end{array}$ \\
\hline & & & & & DLPFC & $20 \mathrm{~min}$ & 5 & (5) & $\begin{array}{l}\text { Ingen signifikant smerte- } \\
\text { reduksjon målt med visuell } \\
\text { analog skala }{ }^{1}\end{array}$ \\
\hline $\begin{array}{l}\text { Soler, } \\
2010(41)\end{array}$ & $\begin{array}{l}\text { Kronisk smerte etter rygg- } \\
\text { margsskade }\end{array}$ & 20 & (16) & 2 & M1 & $20 \mathrm{~min}$ & 10 & $(14)$ & $\begin{array}{l}\text { Ingen signifikant reduksjon } \\
\text { i generell smerte målt med } \\
\text { numerisk skala }\end{array}$ \\
\hline
\end{tabular}

Behandlingseffekt signifikant forskjellig fra placebo $(p<0,05)$

2 Studien hadde overkrysningsdesign

til å gi alvorlige bivirkninger, vil det være nyttig med et felles kvantifiserbart system for registrering og rapportering i fremtidige studier (17). En mer presis og sammenliknbar registrering og rapportering er særlig viktig fordi fremtidige stimuleringsparadigmer som forlenger den kliniske effekten av behandlingen trolig også vil forlenge eventuelle uønskede effekter. Fremtidige studier bør, i likhet med de som er vurdert i denne oversiktsartikkelen, inneholde grundige beskrivelser av prosedyrene. På den måten kan en voksende litteratur gi grunnlag for å vurdere hva som gjør transkranial likestrømsstimulering mer eller mindre virksom.

De fleste studier der man har undersøkt virkningen av transkranial likestrømsstimulering på kroniske smerter har hatt relativt få deltakere og kort oppfølgingstid. Behandlingseffekten hos pasienter med kroniske smertetilstander er lovende, men den smertehemmende effekten lar seg ikke reliabelt reprodusere i studier der man påfører eksperimentell smerte på friske frivillige deltakere (42). Videre kritiseres metoden for at de nevrofysiologiske mekanismene bak den observerte kliniske effekten fortsatt er uklare (12). Likevel, dersom behandlingsmetoden gir symptomlettelse for pasienter med kroniske smerter, vil det være et kost- nadseffektivt bidrag i smertebehandlingen (43). Behandlingen kan også gis utenfor de store sykehusene.

Transkranial likestrømsstimulering kan endre eksitasjon og inhibisjon $\mathrm{i}$ områder av hjernen, og effekten varer lenger enn selve stimuleringen (15). Behandlingsprinsippet er lovende, men man må utøve grundighet og forsiktighet, ettersom det er mange ubesvarte spørsmål knyttet til mekanismene bak behandlingen.

I tillegg til å være potensiell behandlingsmetode kan transkranial likestrømsstimulering være et nyttig instrument i nevrovitenskapelig forskning. Muligheten for ikkeinvasiv manipulering av kortikal eksitabilitet er nyttig når man undersøker sammenhengen mellom cerebrale funksjoner og smerteopplevelse. Mye av den nåværende kunnskapen på dette feltet kommer fra studier der man med funksjonelle hjerneavbildningsteknikker observerer aktiveringsmønstre som oppstår under ekstern stimulering. Med transkranial likestrømsstimulering kan denne aktiveringen manipuleres eksperimentelt, noe som gjør at man kan teste hypoteser om hvordan hjernen prosesserer smerte. Dette kan bidra til ny empirisk kunnskap om patofysiologiske mekanismer involvert i kroniske smertetilstander.

\section{Asbjørn J. Fagerlund (f. 1983)}

er cand.psychol., psykolog ved Smerteavdelingen og ph.d.-stipendiat i Forskningsgruppe for affektivt og kognitivt nevrofag.

Forfatter har fylt ut ICMJE-skjemaet og oppgir følgende interessekonflikter: Han har fått doktorgradsstipend fra Extrastiftelsen.

\section{Martin K. Bystad (f. 1982)}

er cand.psychol., psykolog ved Alderspsykiatrisk avdeling og ph.d.-stipendiat i Forskningsgruppe for affektivt og kognitivt nevrofag. Forfatter har fylt ut ICMJE-skjemaet og oppgir ingen interessekonflikter.

\section{Per M. Aslaksen (f. 1976)}

er cand.psychol., ph.d., førsteamanuensis i Forskningsgruppe for affektivt og kognitivt nevrofag samt spesialist i klinisk nevropsykologi ved Universitetssykehuset Nord-Norge. Forfatter har fylt ut ICMJE-skjemaet og oppgir ingen interessekonflikter.

\section{Litteratur}

1. British Pain Society. Useful definitions \& glossary. www.britishpainsociety.org/

patient_def_glossary.htm (2.4.2012).

2. Bergman S, Herrström P. Högström K et al. Chronic musculoskeletal pain, prevalence rates, and 
sociodemographic associations in a Swedish population study. J Rheumatol 2001; 28: 1369-77.

3. Breivik H, Collett B, Ventafridda V et al. Survey of chronic pain in Europe: prevalence, impact on daily life, and treatment. Eur J Pain 2006; 10: 287-333.

4. Knardahl S. Kroniske smerter - giør vi alt galt? Tidsskr Nor Lægeforen 2001; 121: 2620-3.

5. Loeser JD, Melzack R. Pain: an overview. Lancet 1999; 353: 1607-9

6. Nachemson A. Chronic pain - the end of the welfare state? Qual Life Res 1994: 3 (suppl 1): S11-7.

7. Bair MJ, Robinson RL, Katon W et al. Depression and pain comorbidity: a literature review. Arch Intern Med 2003; 163: 2433-45.

8. Gran JT. The epidemiology of chronic generalized musculoskeletal pain. Best Pract Res Clin Rheumatol 2003; 17: 547-61.

9. Desmeules JA, Cedraschi C, Rapiti E et al. Neurophysiologic evidence for a central sensitization in patients with fibromyalgia. Arthritis Rheum 2003; 48: 1420-9

10. Apkarian AV, Baliki MN, Geha PY. Towards a theory of chronic pain. Prog Neurobiol 2009; 87: 81-97.

11. Stagg CJ, Nitsche MA. Physiological basis of transcranial direct current stimulation. Neuroscientist 2011; 17: 37-53

12. George MS, Aston-Jones G. Noninvasive techniques for probing neurocircuitry and treating illness: vagus nerve stimulation (VNS), transcranial magnetic stimulation (TMS) and transcranial direct current stimulation (tDCS). Neuropsychopharmacology 2010; 35: 301-16.

13. Miranda PC, Lomarev M, Hallett M. Modeling the current distribution during transcranial direct current stimulation. Clin Neurophysiol 2006; 117: 1623-9

14. Mendonca ME, Santana MB, Baptista AF et al. Transcranial DC stimulation in fibromyalgia: optimized cortical target supported by high-resolution computational models. J Pain 2011; 12: 610-7.

15. Nitsche MA, Paulus W. Sustained excitability elevations induced by transcranial DC motor cortex stimulation in humans. Neurology 2001: 57: 1899-901.

16. Nitsche MA, Liebetanz D, Lang N et al. Safety criteria for transcranial direct current stimulation (tDCS) in humans. Clin Neurophysiol 2003; 114: 2220-2.

17. Brunoni AR, Amadera J, Berbel B et al. A systematic review on reporting and assessment of adverse effects associated with transcranial direct current stimulation. Int J Neuropsychopharmacol 2011: 14: 1133-45

18. Gandiga PC, Hummel FC, Cohen LG. Transcranial DC stimulation (tDCS): a tool for double-blind sham-controlled clinical studies in brain stimulation. Clin Neurophysiol 2006; 117: 845-50.

19. Fregni F. Thome-Souza S, Nitsche MA et al. A controlled clinical trial of cathodal DC polarization in patients with refractory epilepsy. Epilepsia 2006: 47: $335-42$

20. Nitsche MA, Paulus W. Noninvasive brain stimulation protocols in the treatment of epilepsy: curren state and perspectives. Neurotherapeutics 2009 6: $244-50$.

21. Boggio PS, Rigonatti SP, Ribeiro RB et al. A randomized, double-blind clinical trial on the efficacy of cortical direct current stimulation for the treatment of major depression. Int J Neuropsychopharmacol 2008; 11: 249-54.

22. Nitsche MA, Boggio PS, Fregni F et al. Treatment of depression with transcranial direct current stimulation (tDCS): a review. Exp Neurol 2009; 219 14-9.

23. Boggio PS, Sultani N, Fecteau S et al. Prefrontal cortex modulation using transcranial DC stimulation reduces alcohol craving: a double-blind sham-controlled study. Drug Alcohol Depend 2008; 92: 55-60.

24. Boggio PS, Zaghi S, Villani AB et al. Modulation of risk-taking in marijuana users by transcranial direct current stimulation (tDCS) of the dorsolateral prefrontal cortex (DLPFC). Drug Alcohol Depend 2010; 112: 220-5.

25. Fregni F. Liguori P. Fecteau S et al. Cortical stimu lation of the prefrontal cortex with transcranial direct current stimulation reduces cue-provoked smoking craving: a randomized, sham-controlled study. J Clin Psychiatry 2008; 69: 32-40.

26. Hummel F, Celnik P, Giraux P et al. Effects of noninvasive cortical stimulation on skilled motor func tion in chronic stroke. Brain 2005; 128: 490-9.

27. Boggio PS, Nunes A, Rigonatti SP et al. Repeated sessions of noninvasive brain DC stimulation is associated with motor function improvement in stroke patients. Restor Neurol Neurosci 2007; 25: $123-9$.

28. Boggio PS, Ferrucci R, Mameli F et al. Prolonged visual memory enhancement after direct current stimulation in Alzheimer's disease. Brain Stimulat 2012; 5: 223-30

29. Roizenblatt S, Fregni F, Gimenez R et al. Site-specific effects of transcranial direct current stimulation on sleep and pain in fibromyalgia: a randomized, sham-controlled study. Pain Pract 2007; 7 297-306.

30. Fregni F, Gimenes R, Valle AC et al. A randomized, sham-controlled, proof of principle study of transcranial direct current stimulation for the treatment of pain in fibromyalgia. Arthritis Rheum 2006; 54: 3988-98.

31. Nitsche MA Fricke $K$, Henschke U et al. Pharmacological modulation of cortical excitability shifts induced by transcranial direct current stimulation in humans. J Physiol 2003; 553 : 293-301.

32. Alonzo A, Brassil J, Taylor JL et al. Daily transcranial direct current stimulation (tDCS) leads to greater increases in cortical excitability than second daily transcranial direct current stimulation. Brain Stimulat 2012; 5: 208-13.

33. Ottosson J-O, Odeberg H. Evidence-based electroconvulsive therapy. Acta Psychiatr Scand 2012: 125: 177-84

34. Nitsche MA, Jaussi W, Liebetanz D et al. Consolidation of human motor cortical neuroplasticity by D-cycloserine. Neuropsychopharmacology 2004; 29: 1573-8

35. Nitsche MA, Paulus W. Excitability changes induced in the human motor cortex by weak transcranial direct current stimulation. J Physiol 2000; 527: 633-9

36. Poreisz C, Boros K, Antal A et al. Safety aspects of transcranial direct current stimulation concerning healthy subjects and patients. Brain Res Bull 2007; 72: $208-14$

37. Bikson M, Datta A, Elwassif M. Establishing safety limits for transcranial direct current stimulation. Clin Neurophysiol 2009: 120: 1033-4.

38. Boggio PS, Amancio EJ, Correa CF et al. Transcranial DC stimulation coupled with TENS for the treatment of chronic pain: a preliminary study. Clin J Pain 2009: 25: $691-5$

39. Antal A, Terney D, Kühnl S et al. Anodal transcranial direct current stimulation of the motor cortex ameliorates chronic pain and reduces short intracortical inhibition. J Pain Symptom Manage 2010; 39: 890-903

40. Fregni F, Boggio PS, Lima MC et al. A sham-controlled, phase II trial of transcranial direct curren stimulation for the treatment of central pain in traumatic spinal cord injury. Pain 2006; 122: 197-209.

41. Soler MD, Kumru H, Pelayo R et al. Effectiveness of transcranial direct current stimulation and visual illusion on neuropathic pain in spinal cord injury. Brain 2010; 133: 2565-77.

42. Jürgens TP Schulte A, Klein T et al Transcranial direct current stimulation does neither modulate results of a quantitative sensory testing protocol nor ratings of suprathreshold heat stimuli in healthy volunteers. Eur J Pain 2012; 16: 1251-63.

43. Zaghi S, Heine N, Fregni F. Brain stimulation for the treatment of pain: A review of costs, clinical effects, and mechanisms of treatment for three different central neuromodulatory approaches. J Pain Manag 2009; 2: 339-52.

Mottatt 3.1. 2013, første revisjon innsendt 11.6. 2013, godkjent 16.9. 2013. Redaktør Kristin Viste. 